ÁREA ABIERTA. Vol.13. $n^{\circ}$ 2. Julio 2013.

http://dx.doi.org/10.5209/rev_ARAB.2013.v34.n2.42622

Referencia: AA35.1207.172

"FRACTURA Y FRAGMENTACIÓN DEL HÉROE

Y EL VILLANO CINEMATOGRÁFICO ACTUAL

EN 'EL PROTEGIDO' DE M. NIGHT SHYAMALAN"

AUTOR: Gabriel GARCÍA MINGORANCE

Universidad Rey Juan Carlos

\title{
Fractura y fragmentación del héroe y el villano cinematográfico actual en "El protegido" de M. Night Shyamalan
}

\section{Fracture and Fragmentation of Actual Cinema Hero and Villain in M. Night Shyamalan's "Unbreakable"}




\section{RESUMEN:}

En la actualidad, el héroe cinematográfico ha ido modificándose hasta desdibujarse de tal manera que en muchas ocasiones es confundido, cambiando su percepción, interpretación y construcción arquetípica-narrativa. Uno de esos cambios o mutaciones que hemos encontrado se basa en la fractura y fragmentación del héroe. Dicha fragmentación presenta protagonistas perdidos, ausentes e incapaces de aceptar su identidad que genera consecuencias en la forma de construcción del resto de personajes asociados al héroe y a la trama. En este trabajo analizaremos a un héroe fragmentado concreto y cómo su relación con el antagonista, que consigue recrear $\mathrm{M}$. Night Shyamalan en El Protegido, revela este hecho. La historia de "El Protegido" se construye de una manera muy peculiar. Esta fragmentación se representa de tal manera que el villano adquirirá cualidades y funciones propias de otros arquetipos presentes en el viaje del héroe, como el mentor, para aparentemente ayudarle. Además la trama se construye de manera fragmentada ocultando una amenaza clara que persiga al héroe o que le enfrente a su objetivo o tarea (derrotar al villano). Solo existe una fuerza motora, una especie de viaje centrado en el misterio de la identidad. Finalmente concluiremos con lo que Shyamalan desvela en un giro final mediante la peculiar interacción entre villano y héroe. Descubriremos el por qué de la verdadera naturaleza del protagonista y a su vez de su némesis: seres que yacían incompletos, fragmentados, hasta aceptarse/descubrirse, desfragmentándose.

\section{Palabras clave:}

Héroe Fragmentado, Villano Fragmentado, Cine Actual, M. Night Shyamalan, Forja del Héroe, Aprendizaje Trágico, Amenaza Fragmentada, Giro Inesperado.

\section{ABSTRACT:}

Today, the contemporary film hero has changed disappearing and often being confused, changing their perception, interpretation and narrative construction-archetypal. One of these changes or mutations that we found is based on the fracture and fragmentation of the hero. Such fragmentation involves lost characters feeling absence and being unable to accept their identity that generates consequences in the way of construction of the rest of the associated hero characters and plot. In this paper we analyze a particular fragmented hero, David Dunn, and how close is the relationship between him and the antagonist, Elijah Price, written and directed by M. Night Shyamalan in "Unbreakable", revealing this as a fact. As a result we will see how the story of Unbreakable is constructed in a very peculiar way. This fragmentation is represented so that the villain will acquire qualities and functions of other archetype present in the hero's journey, as a mentor, to apparently help David Dunn. Also the plot is constructed so fragmented that hides a clear threat that pursues the hero, confronting him, veiling his goal or task (defeat the villain). There is only one driving force, a kind of journey focused on the mystery of identity. Finally 
we conclude with what Shyamalan twist ending reveals, a unique interaction with the villain and hero, discovering why the true nature of the protagonist and his nemesis turns: they are incomplete, fragmented, until they accept/discover themselves.

\section{Key words:}

Fragmented Hero, Fragmented Villain, Actual cinema, M. Night Shyamalan, Hero's Task, Tragic Quest, Fractured Threat, Plot Twist. 
Investigar al héroe en la actualidad nos revela lo complicado de la tarea. Nos informa que al igual que les sucede a muchos arquetipos y esquemas narrativos ha cambiado de manera irremediable. El caso que nos ocupa, del que hablaremos en las siguientes páginas, trata sobre la extrema fragmentación del héroe: sufre tal dispersión que para identificarlo debemos también estudiar a su mayor enemigo, el villano.

Este proceso conlleva múltiples perspectivas, pues, dependiendo del punto de vista que utilicemos, pueden confundirse dichos arquetipos en una historia. Es lo que sucede en la cinematografía actual conllevando cierto peligro para cualquier investigación que se adentre en el tema. Sin embargo, hemos localizado algunos patrones narrativos y arquetípicos, ejemplificados en las siguientes páginas, que nos permitirán extrapolar al resto de narraciones en las que el héroe se encuentra fragmentado, tal y como era concebido en las tragedias de la Grecia clásica hasta nuestros tiempos.

Para ello, vamos a explicar en primer lugar qué entendemos por fractura y fragmentación del arquetipo heroico clásico, cuales son sus consecuencias y cuál es su esencia narrativa. Repasaremos cuáles son las virtudes, atributos y funciones que configuran al héroe clásico para así poder identificar el momento o, al menos, el por qué y la manera en que cambia de manera irreversible, fragmentándose.

En segundo lugar, vamos a visitar un personaje heroico cinematográfico concreto, David Dunn, que es el protagonista de la película El Protegido, escrita, dirigida y producida por el cineasta M. Night Shyamalan. Analizaremos las características propias de este héroe que, como podemos adelantar, difiere en parte del nuevo arquetipo o mutación que proponemos pero que nos ayudará a desarrollar varios conceptos que afrontan estos personajes fragmentados. Uno, el tipo de itinerario o viaje del héroe y en segundo lugar, su psique interna 0 ethos $^{l}$ fracturada y el aprendizaje que lleva a cabo para desfragmentarse.

En tercer y último lugar veremos otro fenómeno que comporta la utilización de este tipo de héroe en la narración: la posibilidad de la mutación o subversión del resto de arquetipos o personajes asociados al mismo, en este caso el villano de la historia. También se encuentra fragmentado y su nueva función se halla subvertida pues ejerce las funciones de mentor del héroe. Estudiaremos este caso para descubrir como la relación entre ambos genera toda una serie de consecuencias que generan un patrón narrativo propio, así como la resolución sorpresiva de El Protegido evoca ciertos conceptos a analizar.

Finalmente concluiremos con ciertas nociones que permitan identificar este fenómeno y que configuren un panorama abierto al estudio de dicho arquetipo, tramas e historias relacionas con el héroe fragmentado.

\footnotetext{
${ }^{1}$ Ethos proviene del griego y significa "conjunto de rasgos y modos de comportamiento que conforman el carácter o la identidad de una persona o una comunidad." En Real Academia Española. Etos. Diccionario de la lengua española (23. ${ }^{a}$ ed.). Recuperado de $\mathrm{http}: / /$ lema.rae.es/drae/? $\mathrm{val}=\mathrm{etos}$
} 


\section{El héroe fragmentado como mutación del héroe clásico}

A lo largo de los años el héroe ha ido perdiendo las virtudes clásicas que le conferían los autores de la antigüedad como Aristóteles o San Agustín, especialmente durante la Edad Media, que respondían a las cuatro virtudes del alma por las que la gente corriente desearía emular al héroe: prudencia, justicia, templanza y fortaleza. ${ }^{2}$ Así lo explica Aristóteles": prudencia, "la virtud del intelecto conforme a la cual bien pueden deliberar", justicia, "la virtud mediante la cual todos y cada uno tienen lo suyo, y como manda la ley", templanza, la virtud "que frente a los placeres del cuerpo se comportan así como marca la ley" y fortaleza o "valentía mediante la cual son realizadores de hermosas acciones en medio de los peligros.". Todo héroe clásico debía poseer o hacer gala de estas virtudes en aras de defender al inocente, al desvalido o al mundo en general. Una vez dispusiera de las mismas, es decir, hubiera completado su forja, comenzaba la tarea del héroe que, simplificando al máximo, consiste en proteger y servir ${ }^{4}$, lema utilizado por la policía de Los Ángeles serigrafiado en el exterior de la mayor parte de su flota de coches. "La vocación del héroe es el sacrificio por sus protegidos y a ellos se debe, aunque su vida esté en juego. Resulta inconcebible un héroe que sólo busque su beneficio particular. Esto parece más bien propio del villano, aunque también el héroe posmoderno, pragmático, tiende a protegerse y a servirse a sí mismo. Se trata de una moda cínica de finales de siglo XX que intenta diluir al héroe con el villano." ${ }^{5}$

La tradición clásica nos revela que el héroe es "función y cualidad del personaje; es decir, se trata de aquel personaje sobre quien recae el peso de la acción y que manifiesta la orientación del relato, pero, al mismo tiempo, es aquel que desempeña funciones que están pautadas como heroicas." "Siendo el reino de la aventura donde despliega todos sus atributos y funciones de héroe. Una aventura que obliga al personaje a afrontar "la ruptura vital que supone el cambio del tiempo cotidiano, rutinario, por otro al que podríamos denominar dramático"7, es decir, abandonando su ambiente doméstico una vez es llamado a la aventura en pos de lo desconocido. Así mismo la predestinación y el "itinerario, el trayecto que debe recorrer el héroe en el transcurso de su aventura"8 es un viaje circular que lo devolverá a su casa, al ámbito cotidiano, transformado, con una nueva identidad pues se habrá enfrentado a innumerables peligros, a la muerte misma. Más o menos, estas serían las características claves del héroe tal y como lo conocemos y que todavía se explotan en la narrativa tanto cinematográfica como literaria, como

\footnotetext{
${ }^{2}$ Aristóteles cita en concreto ocho virtudes "justicia, valentía, templanza, magnificencia, magnanimidad, liberalidad, prudencia y sabiduría". Sin embargo señala como más importantes las citadas arriba por su carácter desinteresado, típicas de los héroes: "es necesidad que las más grandes virtudes sean las más útiles para los demás, ya que la virtud es capacidad benéfica. Y por eso honran principalmente a los justos y los valerosos." En ARISTÓTELES, Retórica, Universidad Nacional Autónoma de México, México D.F., 2002, p. 36.

${ }^{3}$ Cfr. ARISTÓTELES, p. 37.

${ }^{4}$ SANCHEZ-ESCALONILLA, A., Estrategias de guión cinematográfico, ed. Ariel, Barcelona, 2002,

p. 94.

${ }^{5}$ Ibíd.

${ }^{6}$ CUADRADO, A., MONDELO, E., La desaparición del héroe: espacio y épica en el reality., Actas Do III SOPCOM, VI LUSOCOM E II IBÉRICO, Volumen I, 2005, p.633.

${ }^{7}$ Cfr., CUADRADO, A., MONDELO, E., p. 634.

${ }^{8}$ Ibíd.
} 
apuntan Xavier Pérez y Nuria Bou ${ }^{9}$ donde podemos encontrar infinidad de ejemplos. Desde fantasías de aventuras como El Señor de los Anillos y La Guerra de las Galaxias, pasando por leyendas -Robin Hood, 300-, mitos -Furia de Titanes, Inmortals, Troya-, hasta relatos inspirados en la realidad antigua -Gladiator, Centurión- o moderna -La Jungla de Cristal, Arma Letal, El último Gran Héroe-

Como vemos en estos ejemplos, sigue manteniéndose en la cinematografía actual las características, atributos, funciones heroicas, así como la tarea y el viaje del héroe. Sin embargo, en cierto número de casos cinematográficos actuales los protagonistas, los héroes, no saben exactamente para qué están en el mundo y sobre todo, lo más importante, carecen o desconocen las virtudes fundamentales, no pudiendo cumplir su misión, su aventura, con las consecuencias que ello conlleva. A dicha anomalía la hemos denominado como fractura y fragmentación del héroe en la cinematografía actual, que resume esta pérdida del héroe clásico en determinados relatos y su posterior transformación.

Desde nuestro punto de vista, la concepción clásica cinematográfica del héroe comienza a desdibujarse según llegamos a los años 70 y 80, donde la llamada época posmoderna ejerce su mayor influencia. Encontramos nuevos arquetipos y protagonistas atormentados que olvidan sus cualidades heroicas, o las apartan para convertirse en villanos incluso, según nos vamos acercando a los años 90, a pesar de realizar actos heroicos, dichos personajes desconocen serlo, pues no poseen ninguno de los requisitos necesarios. Un ejemplo revelador es la película Héroe por Accidente (1992) interpretada por Dustin Hoffman. En ella vemos cómo un padre divorciado, desahuciado y completamente destartalado, que incluso es ladrón de poca monta, salva a 300 personas de morir en un accidente de un Boeing 747 en Manhattan. Bajito, sin afeitar, desaliñado, es suplantado por otro personaje que utiliza su éxito, Andy García, que sí cumple con las expectativas del héroe clásico y del marketing televisivo, guapo, elocuente y justo. Sin embargo, al descubrirse la verdad al final de la historia, observamos cómo y de qué manera, el héroe se ha cotidianizado, como sucede en esta película, hasta confundirse y olvidarse. En este caso vemos el fenómeno de negación que afecta a otro personaje/héroe paradigmático como es Peter Pan. En Hook (1991), Peter Banning, un hombre de mediana edad, corriente, gordo y hastiado que vive obsesionado por su trabajo, ha olvidado que en realidad es Peter Pan, el niño que no quería crecer. Sólo mediante su viaje a Nunca Jamás, en busca de sus hijos le hará recordar quién es en realidad, venciendo a su terrible enemigo James Garfio: "Tú sabes que no eres realmente Peter Pan, ¿̇verdad? Esto es sólo un sueño. Cuando despiertes serás sólo Peter Banning: un hombre egoísta que debe demasiado, que está obsesionado por el éxito y huye de su mujer y sus hijos."

Así, "frente a la narración clásica, en la que el héroe rompe con la rutina, asistimos a la potenciación del tiempo cotidiano frente al dramático"10. El ámbito doméstico se convierte en el lugar de la acción, lo extraordinario no aparece y por lo tanto se

\footnotetext{
${ }^{9}$ BOU, N., PÉREZ, X., El Tiempo del Héroe. Épica y Masculinidad en el cine de Hollywood, Ediciones Paidós, Barcelona, 2000, pp. 55-89.

${ }^{10}$ Cfr., CuAdRADO, A., MONDELO, E., p. 635.
} 
desvanece la necesidad de comportamientos heroicos. Aparentemente desaparece el viaje del héroe, no hay itinerario, ni umbrales que cruzar. "En el nuevo tipo de relato que propone nuestra época no se trata de presentar al héroe clásico ni siquiera al héroe fracasado y descreído y un tanto cínico de la modernidad sino que lo que se nos propone es el tipo corriente, la persona devenida en personaje, alguien cotidiano, alguien como nosotros, al que le ocurren las mismas cosas y que reacciona de manera similar a como nosotros lo haríamos en parecidas situaciones."11

Este ámbito de acción cotidiano comporta una realidad que le resulta extraña al héroe, incomprensible, inestable ${ }^{12}$, alejada de los patrones narrativos clásicos que, paradójicamente, situaba el ámbito doméstico como un lugar para descansar de los peligros, de los seres fabulosos e incompresibles del mundo mágico o extraordinario. Estos héroes cotidianos perciben la realidad de todos los días como "un mundo codificado y este hecho agrava su aislamiento, en especial dentro del ámbito afectivo."13 Y esta experiencia del mundo codificado o realidad inestable comporta las siguientes consecuencias. En primer lugar, el proceso resultante puede proceder de un trauma o bien de la propia experiencia inteligible con el entorno cercano del protagonista. En segundo lugar, si dicho trauma se vuelve insuperable o no se soluciona comienza el aislamiento y fractura del personaje que, finalmente y en su tercer estadio, termina con su atrincheramiento ${ }^{14}$, una versión más acusada del propio aislamiento (en muchos casos violenta, contra sí mismo o su comunidad). Por tanto, el héroe despojado de toda cualidad, función, objetivo heroico en apariencia, perdido en un mundo cotidiano caótico, aislado por una sociedad que supuestamente no le necesita, se quiebra, se rompe. Esa realidad contingente, incomprensible lo que hace es resaltar un conflicto entre la psique o ethos individual ${ }^{15}$ del héroe con el ethos social que le rodea en el ámbito de la ficción. Aquí se consuma la fractura del héroe.

La fractura también puede considerarse una forma de mutación que otros autores ${ }^{16}$ han apuntado como caída o descenso del héroe. Este tipo de esquemas heroicos comparten similitudes pues representan la corrupción, disolución o bien la conversión del héroe en villano debido al sacrificio (por amor normalmente), a la mancillación de los prefectos y virtudes heroicas (el asesinato de inocentes)... En definitiva, un proceso traumático que en algunos casos comporta un proceso de redención o reaprendizaje, para su posterior ascenso/purificación o bien la destrucción total y su fin como villano. Esta fractura/trauma

\footnotetext{
${ }^{11}$ Cfr., CUADRADO, A., MONDELO, E., p. 636.

${ }^{12}$ ROAS, D., Tras los límites de lo real: una definición de lo fantástico, Editorial Páginas de Espuma, Madrid, 2012, p. 161

${ }^{13}$ SÁNCHEZ-ESCALONILLA, A., "Incomunicación y trauma en el cine de M. Night Shyamalan", FILMHISTORIA Online, Vol. XXII, n 1, 2012, p. 4.

${ }^{14}$ SÁNCHEZ-ESCALONILLA, A., "Hollywood y el arquetipo del atrincherado. Clave dramática y discurso político del 11-S", Revista Latina de comunicación social, n 64, 2009, pp. 926-927.

15 PRÓSPER RIBES, J., "El Héroe Clásico en el relato cinematográfico", Área Abierta, n 13, 2006, pp. 3-4. Recuperado de: http://revistas.ucm.es/index.php/ARAB/article/view/ARAB0606130005A/4175

16 TOBIAS, R., "Tramas 19\&20: Ascenso y Caída", El guion y la trama: fundamentos de la escritura dramática audiovisual, Ediciones Internacionales Universitarias, Madrid, 1999, pp. 245-253.
} 
suele ser descrito como un pasaje de pesadilla, una experiencia de sueño ${ }^{17}$ por tierras sombrías hasta el despertar del héroe.

Otra perspectiva relaciona esta fractura o disolución del arquetipo heroico con su muerte o su desaparición. Como propone Ricardo Forster "el héroe ha muerto, la historia se descompone en millones de fragmentos que lejos de armar un rompecabezas lo único que evidencian es el caos de una realidad estallada, de una temporalidad que gira alocadamente sin ningún horizonte de sentido ni ninguna posibilidad de orientación" ${ }^{18}$. Otros autores apuntan que esa muerte proviene del mero hecho de la inacción. El héroe y sus gestas dentro del espacio dramático son eternas, intemporales, a diferencia de las historias que suceden en el ámbito cotidiano donde el tiempo adquiere un significado, una finitud, que el arquetipo del héroe sufre. Es "el tiempo destructor, o lo que es lo mismo, la muerte inmovilizadora, contra la que el héroe se defiende mediante la acción continua, la lucha que ratifica que está vivo"19. Cuando esa acción cesa, el objetivo y la existencia del héroe llegarían a su fin.

Sin embargo, desde nuestro punto de vista esto no sucede del todo así. Esta desaparición no responde a la muerte o el olvido del héroe sino a una fragmentación del mismo. Al fracturarse pasa a un estado latente o de equilibrio basado en la negación de su identidad. Este estado produce ausencia, tristeza, depresión e incapacidad comunicativa en los héroes. Sólo mediante la irrupción de lo extraordinario se generará un conflicło que le haga entrar en acción o alteración. Después de la quiebra o ruptura aún permanecen los restos de los elementos reconocibles del héroe que nos hace llegar a la siguiente conclusión: Fruto de este conflicto nace el héroe fragmentado, un personaje que comprende que su vida está incompleta que necesita recomponer sus piezas a lo largo de la historia, resolver el misterio que le acosa. Debe reconocerse como héroe, tener una profunda anagnórisis de las virtudes que contiene, aceptarlas y, por lo tanto, recibir plenamente su nueva identidad heroica. Así, podrá actuar independientemente del hastío de la sociedad en la que vive, de la que necesita una renovación o una nueva visión de la misma.

\section{David Dunn como "héroe fragmentado" actual: el "aprendizaje trágico"}

El héroe que hemos escogido para plantear esta teoría es David Dunn, interpretado por Bruce Willis, en la película El Protegido, escrita y dirigida por M. Night Shyamalan. El argumento nos traslada a la Filadelfia actual donde un guardia de seguridad hastiado del mundo, deprimido por una vida que no le llena y que su familia no consigue dulcificar, se ve envuelto en el mayor accidente de tren de la historia de la Costa Este Americana. En dicho incidente todos los pasajeros mueren salvo David Dunn, que sale ileso del percance.

\footnotetext{
17 No por casualidad Trauma (herida) comparte raíz etimológica con la palabra alemana Traum, cuyo significado es sueño. Forma parte de la base del psicoanálisis para la interpretación de sueños para la resolución de trastornos psicológicos.

${ }^{18}$ FORSTER, R., "La muerte del héroe", Pensamiento de los confines, n 9-10, agosto, 2001, p. 74.

${ }^{19}$ Cfr., BOU, N., PÉREZ, X., P. 25.
} 
"Se levanta de la camilla en una imagen de resurrección semejante a las que desatan la acción en Kill Bill (2003) y El hombre sin pasado (2002). Como señala Joseph Campbell en su descripción del monomito, es decir, del esquema heroico elemental." una historia construida a la medida de Shyamalan, con un giro final revelador que más adelante desvelaremos. Desde la premisa dramática, que en los primeros minutos del film queda patente mediante una reflexión homenaje al mundo del comic, descubrimos cómo de cotidiano se nos presenta el protagonista del relato y a la vez tan extraño. Sin darnos cuenta David ha atravesado las fronteras de su ámbito doméstico, al menos dentro de un viaje interior, caminando desorientado, resucitado: "una vez atravesado el umbral, el héroe se mueve en un paisaje de sueño poblado de formas curiosamente fluidas y ambiguas, donde debe pasar por una serie de pruebas" ${ }^{21}$.

David es un hombre de mediana edad que intenta ligar con una pasajera del tren y al que no le gustan especialmente los niños. El problema de este personaje es que no sabe quién es, o, mejor dicho, jamás se lo había preguntado hasta el accidente de tren. Este extremo, como venimos diciendo, es cotidiano y, por supuesto, totalmente alejado del héroe clásico que sí acertaba a buscar su camino guiado por las señales o por un mentor. Así que, el héroe fragmentado debe recomponer sus piezas, partiendo de su propio motor de acción, de sus experiencias mundanas. Necesita apoyos, guías fundamentales, una relación estrecha con algo parecido a un mentor, el arquetipo clásico del sabio anciano, aquel que descubre al héroe y lo guía a través de la aventura. Aquí es donde comienza nuestra prospección, desde el mismo momento en que David, recibe una nota pegada en el limpiaparabrisas de su coche, "¿Cuantos días has estado enfermo en tu vida?"

El hecho de que David se encuentre fragmentado radica en que una vez fue un héroe completo y en un determinado momento se fracturó. Eso sucede en un orden cronológico anterior a la película (que más adelante se nos muestra mediante un flashback revelador). Durante su estancia en la Universidad de Filadelfia era un gran jugador de fútbol americano, una auténtica estrella con un futuro prometedor, un héroe en definitiva que se ve truncado. Una noche sufre un terrible accidente de coche del que sale ileso. Sin embargo, su novia, Audrey, está a punto de morir. Es entonces cuando decide fingir una lesión para proteger a su futura mujer Audrey, por amor, abandonando su acción heroica. Comienza así a fragmentarse hasta desaparecer, aparentemente, lejos de la fama del deporte, como guardia de seguridad. Thomson ${ }^{22}$ y Castrillón ${ }^{23}$ analizan este extremo. Comporta ciertas consecuencias entre las que destaca la incapacidad afectiva de David tanto para ser padre y marido de Audrey como su completa infelicidad, necesitada de una deconstrucción y reconstrucción posterior de su psique.

\footnotetext{
${ }^{20}$ PINTOR IRANZO, I. "Los Desnudos y los muertos: La representación de los muertos y la construcción del otro en el cine contemporáneo: El Caso de M. Night Shyamalan", Formats Revista de Comunicación Audiovisual, n4, 2005, p. 11.

${ }^{21}$ CAMPBELL, J., El Héroe de las mil caras: psicoanálisis del mito, Fondo de Cultura Económica, México D.F, 1959, p. 94.

${ }^{22}$ THOMSON, I., "Deconstructing the Hero", Heidegger, Art, and Postmodernity, Cambridge University Press, 2011, pp. 100-129.

${ }^{23}$ CASTRILLÓN, J. L., "La reconstrucción del héroe: El protegido de M. Night Shyamalan", Trama y Fondo, n 20 , 2006, pp. 125-140.
} 
El accidente de tren resulta clave tanto para poner en marcha la historia, como para revelarnos el carácter de la aventura de David. Al final de la película se desvela que él ha sido el causante del mismo, aunque sea indirectamente, por su inacción y su condición heroica fragmentada. Este incidente provoca la ruptura temporal de la vida del héroe fragmentado, es una descarga muy profunda sobre su aparente mundo cotidiano, la alteración que señalan algunos autores como Eugene Vale ${ }^{24}$.

Como afirmábamos anteriormente, este tipo de héroe no abandona el ambiente doméstico, no hace ningún viaje, ni aventura, ni, aparentemente, atraviesa ningún umbral o línea imaginaria dentro del itinerario del héroe. "David emprende lo que Xavier Pérez ha denominado un aprendizaje trágico (2002) que consiste no sólo en el desarrollo de una anagnórisis de su supervivencia equiparable a la que debía desarrollar Crowe a partir de su muerte en El Sexto Sentido, sino también en un crudo enfrentamiento con la pesadez del tiempo que permite una relectura dramática del superhéroe de historieta." 25 Este aprendizaje trágico lo vislumbramos ya cuando David sale del hospital ante la mirada de estupor de los familiares de los accidentados y cuando asiste a la misa funeral por las víctimas fallecidas en el accidente, algo que como a la mayor parte de supervivientes de terribles tragedias, le provoca un profundo sentimiento de culpabilidad y una pregunta, "¿por qué no yo?".

Esa extraña pregunta a la que hacíamos referencia antes que encuentra David Dunn sobre el parabrisas, en principio fácil de responder para cualquier persona, desencadena una serie de acontecimientos que llevan a David, nuestro héroe fragmentado, a contactar con Elijah Price, un vendedor de comics de Filadelfia, autor de dicha nota. Aquí arranca la extraña relación entre David y Elijah, un afroamericano propietario de una tienda, o mejor dicho, una galería de arte dedicada al comic, llamada "Limited Edition". La función narrativa de Elijah Price comienza a definirse desde el primer momento en que aparece en el film: desde su nacimiento como un niño de cristal, enfermo de una rara dolencia denominada osteogénesis imperfecta, que lo hace vulnerable a cualquier golpe o caída. En el polo opuesto, se encuentra David que según el razonamiento de este peculiar vendedor de comics, puede ser irrompible, invulnerable, de ahí la pregunta anteriormente formulada, "¿Cuantos días has estado enfermo en tu vida?" Desde el primer momento en que contactan comenzamos a vislumbrar cómo Elijah Price investiga, propone diversas pruebas a David a fin de llegar a una conclusión razonable que resuelva el enigma. En palabras del propio Shymalan:

"Los personajes no entienden el vocabulario del mundo extraordinario, de la ficción fantástica que coexiste en la historia, escondido. La película trata sobre sus acciones intentando comprender dicho vocabulario, al igual que el público lo hace al mismo tiempo. Así que, normalmente, tienen que desconocer ciertos elementos, ser ignorantes al principio de la historia. En muchas

\footnotetext{
${ }^{24}$ VALE, E., "Alteración y ajuste", Técnicas del guión para cine y televisión, Gedisa, Barcelona, 1996. pp. 96-97.

${ }^{25}$ Cfr. PINTOR IRANZO, I., p. 11.
} 
ocasiones introduzco un personaje que informa de las reglas del mundo sobrenatural de una manera en principio no muy creíble, pero que según avanzamos resultan ser las verdaderas."26

Esos dos personajes en El Protegido son por supuesto Elijah Price (un vendedor excéntrico de comics) y el hijo de David, Joseph, que creen en que quizás ese personaje que se levanta triste por las mañanas es en realidad un héroe, explicándonos cuales son las condiciones necesarias para serlo. Sólo existe un pero: David sí ha estado enfermo alguna vez en su vida, se lesionó en un grave accidente de coche en la rodilla junto a su novia (actual mujer), Audrey, terminando su carrera fulgurante en el fútbol americano. Sin embargo Elijah insiste, insiste intentando hacer ver a David las coincidencias o bien los talentos y poderes que él ni siquiera se da cuenta que posee, talentos que hacen de Elijah su némesis perfecta: "Si hay alguien igual a mí en el mundo y estoy a un lado del espectro, ¿por qué no puede haber alguien opuesto al otro extremo, alguien que no enferme, que no se lesione como los demás y probablemente él ni lo sepa, la clase de persona que hay en los cómic, puesto aquí para proteger a los demás, para cuidarnos?". Para fundamentar su teoría Elijah enumera las cualidades que David parece desconocer de sí mismo, cualidades y atributos heroicos que yacen fragmentados, ocultos a sus ojos:

1. El oficio escogido por David, guardia de seguridad en un estadio de fútbol americano, no es un hecho al azar. Recordemos que la tarea fundamental que desempeña todo héroe es proteger y servir. Elijah Price: "¿Por qué será que de todas las profesiones del mundo, ha elegido la protección?"

2. Para desempeñar dicha tarea los héroes cuentan a menudo con poderes especiales, cuentan con habilidades únicas, atributos que les permiten afrontar los terribles peligros y desafíos a los que han de enfrentarse. En el caso de David es una especie de sentido extrasensorial que le permite detectar el mal, o las amenazas. Dentro de esas habilidades, también se encontraría una especial resistencia al dolor que le conferiría una fortaleza capaz de resistir el choque de dos trenes, como sucede al comienzo de la película. Elijah Price: "A los personajes de comic se les suele atribuir poderes especiales."

3. La tristeza que siente David todas las mañanas, ese profundo sentimiento de desespero y ausencia, como Elijah señala, radica en no saber quién es en realidad y por lo tanto poder actuar en consecuencia. David Dunn: "Es la primera mañana en la que me he levantado y no he sentido tristeza... Pensaba que tenía respuestas."

Estas tres revelaciones o reflexiones que realiza Elijah son sólo tres evidencias, pruebas que David debe aceptar, aprehender por sí mismo y que todo mentor realiza sobre su discípulo, en este caso, inmerso dentro de este aprendizaje trágico, una extraña relación entre un vendedor de comic enfermo y un guardia de seguridad. Aquí es donde se invierte el papel que venimos exponiendo para el villano: comienza a convertirse en su

${ }^{26}$ SHYAMALAN, M. N., Entrevista con el autor, febrero 2011. 
amigo, en el mentor de David. Peter Banning olvidó que era Peter Pan, y David Dunn ha olvidado, se ha negado a sí mismo. En contraposición, Elijah cree en lo extraordinario al igual que Joseph y todas estas evidencias conforman el proceso de desfragmentación del héroe fragmentado.

\section{El "mentor-villano": Elijah Price y la desfragmentación del héroe}

Como todos sabemos si hay héroe también debe haber un villano o antihéroe poseedor "de unas características singulares que le aportan del estereotipo heroico, dotándole de individualidad dramática y verosimilitud con lo que el espectador no tiene necesariamente que identificarse sino sólo comprender." ${ }^{27}$. En El Protegido, este extremo no aparece, salvo en el enfrentamiento con el secuestrador al final. El villano está fragmentado también. La amenaza ${ }^{28}$, la causa contra la que lucha el héroe, está velada, se encuentra en cierta medida a la vista del espectador y de los personajes pero al mismo tiempo oculta. Esta confusión la plantea de la siguiente manera Shyamalan: presenta a Elijah Price como algo más que el villano de la historia, de hecho, a pesar de sus aparentes imperfecciones, veremos que sus funciones son muy diferentes a las de un malvado villano, el opuesto o antihéroe. Esa función que otorga Shyamalan a Elijah y que construye de manera fragmentada y que sólo descubrimos la verdadera perspectiva del personaje al final, es la del mentor del héroe. El villano, en este caso Elijah Price, interpretado por Samuel L. Jackson, está totalmente fragmentado, perdido pues, aunque persigue un objetivo -encontrar a un héroe que demuestre su existencia en el mundo y de sentido a su vida- no lo consigue. Está angustiado como cualquier persona normal o cotidiana, al igual que David: "¿Sabes lo que más miedo da? No saber cuál es tu misión en este mundo, no saber por qué estás aquí. Es una sensación horrible."

Normalmente en las historias de forja o descubrimiento del héroe es la figura del mentor "el personaje siempre necesario que ayudará al futuro héroe a forjarse como tal. La figura del mentor resulta fácilmente reconocible en cualquier sociedad, ya que se puede encontrar reflejada en la figura del padre, del profesor, del tutor. Es decir, el mentor es aquél que, con buenas intenciones, va a guiar el camino del joven héroe, ofreciéndole consejos y mostrándole la sabiduría que debe obtener para ser capaz de desarrollar sus habilidades en futuro" ${ }^{29}$. Es aquel que lo ayuda en la difícil tarea de proteger y servir, aquel que lo dotará de las capacidades, e iluminará el camino a seguir. A menudo se trata de un habitante del mundo mágico o extraordinario que siempre resultaba ser un sabio, un

${ }^{27}$ MONDELO. E, "Del hacer y el decir. Sobre la identidad narrativa de los personajes.", CIC, Servicio de Publicaciones UCM, n² 2, 1996, p. 101.

28 "El protagonista se enfrenta a un peligro invisible. Parafraseando al Héroe de las Mil Caras de Campbell, el monstruo, la amenaza también tendría muchas caras, desconocida, sobrenatural, inidentificable. [...] Recuperar la fe en el mundo de los protagonistas es el objetivo principal de esta herramienta dramática en el cine fantástico. Es lo que hace Shyamalan en sus películas." Traducido a partir de la siguiente referencia, GARCÍA MINGORANCE, G., "Monsters, Feérie Fear, Threaten Global and the Uncanny in the Cinema of M. Night Shyamalan", The Many Forms of Fear, Horror and Terror, Inter-Disciplinary Press, Oxford, United Kingdom, 2009, p. 25

${ }^{29}$ FERNÁNDEZ, E., El Itinerario del héroe mitológico en la cinematografía actual, UCM, Departamento de Comunicación Audiovisual y Publicidad I, Madrid, 2005, p. 51. 
sabio anciano debido a su dilatada experiencia: "la función del mentor consiste en preparar al héroe para que se enfrente a lo desconocido. Puede darle consejos, servirle de guía o proporcionarle pociones mágicas" ${ }^{\prime 30}$.

En el caso que nos ocupa, el mentor del héroe no puede ser de la misma manera. Para desfragmentar al héroe en El Protegido se plantea la posibilidad de que sea el propio villano el que adquiera dichas funciones y cualidades ayudándole a recomponer su identidad. Elijah, efectivamente, es un hombre sabio, no en vano, como él mismo relata, ha pasado la mayor parte de su vida estudiando, leyendo, debido a las innumerables horas de hospital, convaleciente de sus lesiones, postrado ante la mala suerte de haber nacido tan frágil. Night Shyamalan plantea estas cuestiones, desvelando las similitudes y, por tanto, las diferencias que separan a Elijah y David, otorgando a Elijah un protagonismo mayor por encima de David. No se trata de su posición, ni del dinero, o tal vez de la inteligencia. Se trata del conocimiento, de la experiencia, y, sobre todo, de la certeza de saber que hay algo más, una predestinación que designa quién o qué somos. Exactamente igual que en el relato clásico de aventura de forja heroica. El personaje de Elijah, el villano que actúa como mentor, cumple a la perfección las reglas necesarias de todo maestro, de todo investigador que busca encontrar a un héroe en "tiempos mediocres".

Este movimiento en el relato que plantea Shyamalan es algo novedoso en lo referente a estas historias de forja de héroes, más o menos clásicos, en la cinematografía contemporánea. En películas como Batman Begins o Spider-Man 3, el villano también es el mentor o amigo del héroe ya forjado o en proceso de forja. Ra`s al Ghul (Liam Nesson) en Batman Begins instruye a Bruce Wayne (Christian Bale), en las artes marciales para poder enfrentarse a sus enemigos. Sin embargo, terminará apareciendo al final de la historia como el villano que quiere destruir Gotham llevado por el fanatismo de la justicia desmedida. Como vemos en esta película sucede algo parecido, un giro inesperado nos demuestra el verdadero antagonista del héroe, su amigo, su mentor.

Sin embargo, en El Protegido de Shyamalan existe algo más. Ese antagonista, ese villano también está perdido, fragmentado como el héroe, sin una función clara que cumplir. No forma parte de un plan maquiavélico para destruir al héroe o realizar alguna tarea. Supone más una necesidad personal. Así pues su papel en la historia, su investigación como mentor de David Dunn, es una desfragmentación necesaria, una anagnórisis doble tanto para el héroe, como para el villano. Ambos, protagonista y antagonista, ansían encontrar su verdadera identidad, el por qué de su vida, su misión en este mundo, algo que explique, en el caso de Elijah, su terrible enfermedad, y en el de David, su profundo sentimiento de desesperación y depresión. En la mayor parte de sus historias Shyamalan concibe a sus protagonistas como seres que han perdido algo, que son incapaces de tener fe en el mundo, que se presenta como una realidad codificada ${ }^{31}$, ininteligible, perdidos, ausentes, encerrados en sí mismos, como ocurre también en el caso de Señales.

\footnotetext{
${ }^{30}$ VOGLER, C., El viaje del escritor, Ediciones Robinbook, Barcelona, 2000, p. 50.

${ }^{31}$ SANCHEZ-ESCALONILLA, A., Fantasía de Aventuras, Ed. Ariel, Barcelona, 2009, p. 229.
} 
Este itinerario trágico ${ }^{32} \circ$ aprendizaje trágico, paradójicamente, en El Protegido, se construye a través de la acción del villano-mentor, a través de una instrucción con una doble anagnórisis tanto para Elijah Price como para el protagonista, David Dunn. La desfragmentación corre a cargo tanto del héroe como del propio villano-mentor. En palabras del propio director, Night Shyamalan, el proceso sería el siguiente:

\begin{abstract}
"Cambiar o subvertir el arquetipo o paradigma de un personaje corriente, cotidiano enfrentándolo hacia lo desconocido es algo muy atractivo para mí. La resistencia a este cambio, la resistencia a lo desconocido es inherente en el conflicto de las películas y en última instancia la liberación de esa oposición: mostraría las respuestas necesarias, las soluciones para que ese personaje consiga resolver los problemas cotidianos a los que también se está enfrentando." ${ }^{33}$
\end{abstract}

El papel de mentor en la historia es sólo una máscara que lo oculta de su verdadera función, cualidad y arquetipo de villano que desconoce. Elijah Price no busca de forma desinteresada ayudar a David Dunn, guiarle a través de la indeterminación del mundo cotidiano. Actúa movido por su propia angustia vital, en pos de un beneficio personal, para descubrir su identidad que, desafortunadamente, depende de la existencia de un enemigo, un héroe que de sentido a su existencia, a su misión. Elijah al igual que David, no sabe por qué está entre la gente. Lleva años buscando alguien como él, algo que explique su extrema debilidad, una mutación genética de la naturaleza que se encuentre al otro lado del espectro. En el caso de David esta pregunta aparece justo cuando Elijah contacta con él, justo cuando su familia comienza a resquebrajarse por completo, su matrimonio con Audrey no funciona y no ejerce de padre con su hijo Joseph. En el caso de Elijah esa enloquecedora pregunta aparece desde que es un niño cuando por temor a romperse algún hueso se encierra en casa.

Así Elijah se pregunta al borde de perder la esperanza: ¿Cómo alguien irrompible y con una fuerza sobrehumana casi se ahogó en una piscina y tuvo una lesión de rodilla? En una secuencia de El Protegido, Shyamalan revela hasta qué punto estábamos en lo cierto. David es un héroe, efectivamente, y más allá de las virtudes o habilidades que pueda tener, lo es porque posee una de las debilidades fundamentales de los héroes contemporáneos, sobre todo los superhéroes. Todo héroe siempre posee un punto débil, algo que explique su vulnerabilidad ante la sociedad. Como un mensaje revelador, David, escucha en el contestador automático de su casa lo que Elijah ha descubierto: "Era tan evidente, he visto algo que me ha dado la clave... Century Comics 117 . En él un grupo, La

\footnotetext{
32 "el guión de "Señales" se desplaza directamente hacia preocupaciones propias de la teología: su protagonista, el personaje encarnado por Mel Gibson, es un predicador que, a la muerte accidental de su esposa, ha colgado los hábitos y ha perdido la fe. El itinerario dramático del filme, a partir del pretexto de una amenaza extraterrestre, pasa por la recuperación de esa fe, aunque el despliegue visual no la busque en las estrellas, sino en un repliegue protector hacia el sótano de la casa familiar." BOU, N., PÉREZ, X., "Los milagros de Night Shyamalan", Culturas, La Vanguardia, n²6, Barcelona, 2002, p. 26.

${ }^{33}$ SHYAMALAN, M. N., Entrevista con el autor, febrero 2011.
} 
Coalición del Mal, trata de descubrir la debilidad de cada superhéroe porque todos tienen una como usted".

Entonces David comprende y descubre la verdad, su identidad, deshaciendo todas las mentiras que se había contado a sí mismo. El accidente y su lesión formaban parte de su fractura para proteger por amor a Audrey; su temor al agua responde a su debilidad, a su criptonita que algunos autores definen como harmatia ${ }^{34}$ o falla trágica, "una impureza, un error esencial en su comportamiento, que debe superar"35. En este caso evoca la incapacidad de David para relacionarse, muerto en vida, y afectivamente con su familia. Así que solo mediante el amor a su propio hijo y a su familia, para recuperarlos y protegerlos, asume su nueva condición, su ascenso como otros autores dirían, se acerca.

Finalmente, siguiendo las instrucciones de Elijah, "vaya donde haya gente", emprende su tarea heroica que culmina con el rescate de una familia secuestrada por un perturbado. Esta prueba final le enfrenta con la muerte, con su debilidad, el agua. Toda la secuencia muestra una lluvia constante cayendo aplomo sobre David, disfrazado con su enorme chubasquero, como reflejo de "la descomposición moral de una sociedad" 36 , como utiliza Ridley Scott y David Fincher en Blade Runner y Seven, respectivamente. En su enfrentamiento con el perturbado cae a la piscina de agua, donde comienza a ahogarse... Es solo gracias a la intervención de dos niños (que había desatado previamente), que consigue resurgir, decidido y vehemente derrotando al malvado hombre que aún retenía a su madre. Cabe destacar el papel de los pequeños, al igual que el hijo de David, que resalta la capacidad y la fe en lo extraordinario que Shyamalan dota a la mayor parte de estos personajes. Son la base y la salvación del propio héroe fragmentado, pues ven lo que los adultos son incapaces de intuir (como sucede por ejemplo también, en El Sexto Sentido, con Cole Sear).

Shyamalan nos presenta esta profunda anagnórisis, enfatizada con la recuperación de su vida y su familia, la reconciliación con su esposa y su regreso a la paternidad recobrando la fe de su hijo. Es su particular vuelta al hogar, un retorno vicario, sin desplazamiento, pues siempre ha estado ahí, pero encerrado en él, oculto como la amenaza que irremediablemente también va a emerger dentro de la historia. La fractura se ha resuelto y las piezas regresan, los fragmentos se recomponen. El sueño desaparece y al fin David recupera su psique completa, su vida. Con una frase elocuente David lo comenta a su mujer en la cama así: "He tenido una pesadilla..." Audrey le contesta: "ya ha pasado." Y así a la mañana siguiente muestra a su hijo Joseph su hazaña reseñada en un periódico local. Recuperada su posición paterna y afectiva, David pide a su hijo que mantenga el secreto pues, como en la mayor parte de superhéroes modernos tanto de cómic como de cine/televisión, solo la asunción de la doble identidad y el anonimato puede garantizar el éxito de su tarea protegiendo a su familia de sus enemigos y de la propia sociedad.

\footnotetext{
${ }^{34}$ BOAL, A., Teatro del oprimido y otras poéticas políticas, Ediciones de la Flor, Buenos Aires, 1974, P. 55. En Cfr., PRÓSPER RIBES J., P. 4.

${ }^{35}$ Cfr., PRÓSPER RIBES, J., p. 4.

${ }^{36}$ MUÑOZ, J.J., Blade Runner. «Más humanos que los humanos», Ediciones Rialp, Madrid, 1998, p. 63.
} 


\section{Epílogo y conclusiones}

David Dunn se ha desfragmentado, al fin ha recuperado la identidad heroica que se fracturó en mil pedazos. Ahora bien, Shymalan reserva un final sorprendente con un giro inesperado como anticipa a lo largo del film sin que el espectador ni David se percaten. Es una compleja secuencia de flashback donde se presenta este particular desenlace, una anagnórisis doble. David acude a la inauguración de la exposición de comic en la tienda de Elijah. Allí su madre lo recibe antes de que se produzca la anagnórisis final:

- MADRE DE ELIJAH:

Este es uno de los primeros dibujos de Johan Davies. Ve los ojos del malo, son los más grandes de todos. Sí, su aspecto insinúa una perspectiva sesgada de su visión del mundo. No es nada normal.

- DAVID:

No provoca miedo

- MADRE DE ELIJAH:

Sí, es lo que le dije a mi hijo. Aunque los hay de dos clases: existe el malo soldado, que combate al héroe con sus manos; y está la verdadera amenaza, el brillante y malvado archienemigo que combate al héroe con su mente.

David se encuentra con Elijah en las oficinas de su tienda, descubriendo la terrible verdad al darse la mano. Su mentor, la persona que lo ayudaba, es un perturbado que, obsesionado por buscar una respuesta a su terrible estado de salud, ha incendiado y saboteado provocando catástrofes -como el accidente de tren, del que solo sobrevive David, y que pone en marcha la desfragmentación-, sembrando el pánico, asesinando a inocentes. Al fin descubrimos la amenaza y el relato se desfragmenta, mostrando al héroe y al villano tal y como son. Elijah Price: "Ahora que sabemos quién eres tú, sé quién soy yo. ¡No soy un despojo! Todo tiene sentido. En un cómic, ¿̇sabes cómo se nota quién va a ser el malvado? Es justamente el opuesto del héroe y la mayoría de las veces son amigos, como tú y yo."
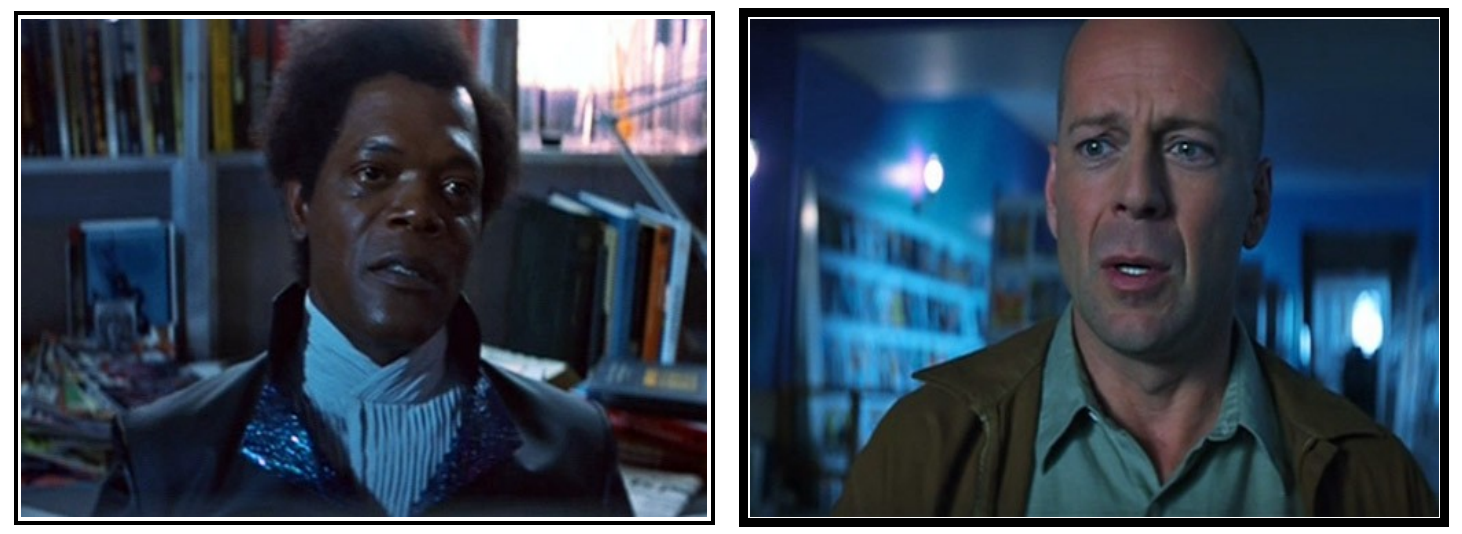
El aprendizaje trágico también termina aquí, con David aterrorizado ante las matanzas que ha hecho Elijah, enajenado buscando una respuesta a su enigma, a su ser... Es entonces cuando, como señala el propio Shyamalan, se refleja "en los ojos del protagonista la verdadera locura"37, el espanto ante lo que está viendo. David entiende las consecuencias de su fractura, comprende lo que habíamos adelantado: su inacción como héroe conlleva el dolor y el sufrimiento de otros. Ese es el peaje de este héroe fragmentado que, recuperado, abandona las oficinas de Elijah para entregarle a la justicia, como un intertítulo señala al final, mientras oye a su enloquecido amigo reafirmar por qué era el villano: "Debí comprenderlo hace mucho tiempo, ¿̇sabes por qué? Por los niños... me llamaban Don Cristal."

Para terminar, vamos a resumir las pautas clave de lo que venimos proponiendo, cómo influyen en la construcción del relato y cómo se resuelven. El héroe clásico en un determinado momento sufre una fractura basada en un conflicto entre su psique y el entorno cotidiano en el que desempeña su función. Esta fractura fragmenta sus características mutando el arquetipo hacia lo que hemos definido como héroe fragmentado. Este personaje se presenta en la acción como alguien corriente que desconoce o se niega a asumir su papel heroico. Necesita recuperar el sentido de su mundo, un lugar que les resulta ininteligible debido a la percepción de la realidad como inestable y codificada. Sólo mediante una forja o desfragmentación consigue recuperar su identidad perdida, descubriendo su falla trágica o punto débil y restaurando sus relaciones afectivas. Este esquema afecta al resto de arquetipos del viaje del héroe de los cuales sólo hemos analizado uno, el villano que también está perdido y fragmentado.

En El Protegido de Shyamalan, Elijah Price, el antagonista, al igual que el héroe, David Dunn, desconoce su verdadera identidad y por tanto su misión en el mundo. Para resolver este enigma el villano asume las funciones y atributos de mentor, buscando y guiando al héroe durante la historia, en este caso a David Dunn. Se produce una forja heroica dirigida por Elijah basada en un aprendizaje trágico, pues inevitablemente el relato nos conduce al enfrentamiento entre ambos y a la asunción de la fractura. Al no conocer su identidad el villano, es decir, la amenaza de la historia contra la que debería luchar el héroe, no existe a priori, contribuyendo así a la confusión, la alteración. Esta es una característica peculiar que propone Shyamalan en El Protegido: el motor de la acción se encuentra invertido, es el villano dotado de las funciones del mentor el que obliga al héroe a ponerse en marcha, a veces solo contactando con él, otras, provocando eventos o incidentes que lo desequilibren.

El regreso al equilibrio se produce cuando descubren su nueva identidad que les permite contemplar su ambiente doméstico, renovado, fruto del enfrentamiento con sus debilidades, temores, con la muerte y su posterior victoria. Finalmente cuando ambos recomponen sus fragmentos el héroe fragmentado deja de serlo y recupera el peso de la narración enfrentándose a la amenaza de la historia, al villano, afrontando su fractura.

${ }^{37}$ SHYAMALAN, M.N., Entrevista con el autor., Febrero 2011. 


\section{BIBLIOGRAFÍA}

ARISTÓTELES, Retórica, Universidad Nacional Autónoma de México, México D.F., 2002.

BALLÓ J., PÉREZ, X., La semilla inmortal, Ed. Anagrama, Barcelona, 1997.

BOAL, A., Teatro del oprimido y otras poéticas políticas, Ediciones de la Flor, Buenos Aires, 1974.

BOU, N., PÉREZ, X., El Tiempo del Héroe. Épica y Masculinidad en el cine de Hollywood, Ediciones Paidós, Barcelona, 2000.

- "Los milagros de Night Shyamalan", Culturas, La Vanguardia, Barcelona, 2002, p. 26.

CAMPBELL, J., El Héroe de las mil caras: psicoanálisis del mito, Fondo de Cultura Económica, México D.F, 1959.

CASTRILLÓN, J. L., "La reconstrucción del héroe: El protegido de M. Night Shyamalan", Trama y Fondo, n² 20, 2006, pp. 125-140.

CAWELTI, J., Adventure, Mystery and Romance: Formula Stories as Art and Popular Culture, University of Chicago Press, Chicago, 1976.

CUADRADO, A., MONDELO, E., La desaparición del héroe: espacio y épica en el reality, Actas do III SOPCOM, VI LUSOCOM e II IBÉRICO, Volumen I, 2005, pp. 633-640.

FERNÁNDEZ, E., El Itinerario del héroe mitológico en la cinematografía actual, UCM, Departamento de Comunicación Audiovisual y Publicidad I, Madrid, 2005.

FITZROY, R., The Hero: A Study In Tradition, Myth, And Drama, Dover Publications, 2003.

FORSTER, R., "La muerte del héroe", Pensamiento de los confines, n 9-10, agosto, 2001, pp. 74-90.

GARCÍA MINGORANCE, G., "Monsters, Feérie Fear, Threaten Global and the Uncanny in the Cinema of M. Night Shyamalan", The Many Forms of Fear, Horror and Terror, InterDisciplinary Press, Oxford, United Kingdom, 2009, pp. 23-34.

GARCÍA-NOBLEJAS, J. J., "Identidad personal y mundos cinematográficos distópicos", en Comunicación y Sociedad, vol. xVII, n² 2, diciembre de 2004.

JAK, S., Writing the Fantasy Film. Heroes and Journeys in Alternate Realities, Michael Wiese Productions, Studio City, 2004.

MONDELO. E, "Del hacer y el decir. Sobre la identidad narrativa de los personajes.", CIC, Servicio de Publicaciones UCM, n² 2, 1996, pp. 99-105. 
MUÑOZ, J.J., Blade Runner. «Más humanos que los humanos», Ediciones Rialp, Madrid, 1998,

NIKOLAJEVA, M., From Mythic to linear. Time in Children's Literature., The Scarecrow Press, Inc. Maryland, 2000.

PINTOR IRANZO, I. "LOS Desnudos y los muertos: La representación de los muertos y la construcción del otro en el cine contemporáneo: El Caso de M. Night Shyamalan", Formats Revista de Comunicación Audiovisual, n4, 2005, pp. 1-28.

PRÓSPER RIBES, J., "El Héroe Clásico en el relato cinematográfico", Área Abierta, n 13, 2006. Recurso online.

RANK, O., El Mito del nacimiento del héroe, Ediciones Paidós, Barcelona, 1992

ROAS, D., Tras los límites de lo real: una definición de lo fantástico, Editorial Páginas de Espuma, Madrid, 2012.

SANCHEZ-ESCALONILLA, A., Fantasía de Aventuras, Ed. Ariel, Barcelona, 2009

- Estrategias de guión cinematográfico, Ed. Ariel, Barcelona, 2002

-"The Hero as a Visitor in Hell: The Descent into Death in Film Structure", Journal of Popular Film and Television, Vol. 32, $n^{\circ}$ 4, 2005, pp. 149-156.

- "Hollywood y el arquetipo del atrincherado. Clave dramática y discurso político del 11S", Revista Latina de comunicación social, n 64, 2009, pp. 926-937.

- "Incomunicación y trauma en el cine de M. Night Shyamalan", FILMHISTORIA Online, Vol. XXII, $n^{\circ} 1,2012$. Recurso online.

SAVATER, F. La tarea del héroe, Ed. Destino, Barcelona, 1992.

SHYAMALAN, M. N., Entrevista con el autor, febrero 2011.

THOMSON, I., "Deconstructing the Hero", Heidegger, Art, and Postmodernity, Cambridge University Press, 2011 , pp. 100-129.

TOBIAS, R., El guión y la trama, Ediciones Internacionales Universitarias, Madrid, 1999.

VALE, E., "Alteración y ajuste", Técnicas del guión para cine y televisión, Gedisa, Barcelona, 1996, pp. 96-111.

VOGLER, C., El viaje del escritor, Ediciones Robinbook, Barcelona, 2000. 